\title{
Quality of Care in a Nursing Home as Experienced by Patients with Dementia
}

This article was published in the following Dove Press journal:

Journal of Multidisciplinary Healthcare

\author{
Ann Karin Helgesen (iD) \\ Dag Werner Larsen ${ }^{2}$ \\ Vigdis Abrahamsen Grøndahl (iD) ' \\ 'Faculty of Health and Welfare Sciences, \\ Østfold University College, Halden, \\ Norway; ${ }^{2}$ Norwegian Nurses' \\ Organisation Viken, Oslo, Norway
}

Background: Dementia care is one of the most rapidly growing areas in health care. Despite this, relatively little is known about the experiences of persons with dementia in relation to quality of care.

Objective: The aim of this study was to describe how persons with dementia in nursing homes experience the quality of care.

Design: A cross-sectional design was used.

Setting and Participants: The study was conducted in a nursing home in Norway. A total of 33 persons with dementia participated.

Results: Respondents' mean age was 86.7 years. More than $80 \%$ reported their health as bad/neither good nor bad. Concerning their satisfaction with staying in the nursing home, two in ten were satisfied. Nearly half answered that they received or sometimes received good help and support when anxious. More than 50\% reported that they only sometimes received or never received good help and support when they felt lonely. The majority perceived that the nurses came/or sometimes came when needed (79\%) and that the nurses had time/ sometimes had time to talk with them $(73 \%)$.

Conclusion: This study reveals that the voice of persons with dementia must be listened to, in order to increase the quality of care in nursing homes. The challenge concerning how living in nursing homes can be more satisfying must be addressed by leaders and nurses in nursing homes, as well as researchers. Special attention must be paid to anxiety, loneliness, and going outdoors.

Keywords: person with dementia, quality of care, nursing home, quantitative

\section{Background}

Dementia care is one of the most rapidly growing areas in health care. ${ }^{1-3}$ Despite this, relatively little is known about the experiences of persons with dementia in relation to quality of care. ${ }^{4,5}$ For a long time, it was assumed by many researchers that the accounts of people with dementia were unreliable. Consequently, their voices were not heard in the context of research, ${ }^{6}$ and they were thus nearly excluded from the trend of involving patients, informal caregivers, and the general public in various aspects of health care, including the health-related research and policy-making that has been highlighted internationally. ${ }^{6}$ Over the last decade, however, experience has shown that many people with dementia can be meaningfully involved in research. ${ }^{7-9}$

Previous research has stated that even if there has been considerable effort devoted to improving elderly patient care in recent years, the reported quality of care is still relatively low ${ }^{10}$ and thus has the potential for further improvement. ${ }^{11-13}$
Correspondence: Ann Karin Helgesen Faculty of Health and Welfare Sciences, Østfold University College, Halden I757, Norway

Email ann.k.helgesen@hiof.no
Journal of Multidisciplinary Healthcare 2020:13 1947-1955

1947 
Patient involvement is essential to developing and carrying out person-centered care ${ }^{14}$ and appropriate care plans. ${ }^{15}$ Both are important elements needed to preserve vulnerable persons' dignity and well-being ${ }^{16,17}$ and essential components of quality-care delivery. ${ }^{18}$

Patients' perceptions of care quality can be measured in different ways. ${ }^{19}$ In this study, an adapted version of the Quality from the Patient's Perspective - dementia care $(\mathrm{QPP}-\mathrm{DC})^{4}$ questionnaire, as found in Wilde et al, was used. $^{20-22}$

\section{Aim}

The aim of the study was to describe how persons with dementia in nursing homes experience the quality of care.

\section{Methods}

A cross-sectional design was used. Face-to-face interviews were carried out using the QPP-DC questionnaire with fixed response alternatives.

\section{Setting and Participants}

The study was conducted in a nursing home in Norway. The nursing home consists of six units and houses 64 people. Permission was obtained from the nursing-home director and heads of units prior to commencement.

Residents who met the following inclusion criteria were invited to participate: they had been diagnosed with dementia, had given his/her written consent and was willing to participate, was able to communicate in an interview situation, and his/her health status permitted participation according to the head of the unit's judgement.

Assessment concerning the person's ability to participate in the study was conducted by the second author in cooperation with health-care personnel who knew the person well. In addition, the Mini-Mental State Examination (MMSE) was used to assess the cognitive abilities of the respondents. ${ }^{23,24} \mathrm{~A}$ total of 37 persons with dementia met the inclusion criteria and were included in the study. Among these, one interview was canceled as the person was sceptical about signing the consent form, and three interviews were terminated because of inability to respond to the questions due to aphasia or challenging behavior. This yielded a final study group of 33 respondents, which resulted in a response rate of $51.6 \%$ among the residents in the nursing home.

\section{Data Collection}

The interviews were conducted in respondents' rooms. Each question in the questionnaire, including the response scale, was read aloud to the respondents by the interviewer, who then wrote their responses on the scales. The interviewer followed a written user manual concerning how to use the questionnaire and tried to follow the manual strictly. If the respondent did not understand a question, the interviewer tried to rephrase it or illustrate its meaning by providing an example, eg, by pointing at the wheelchair when the question concerned access to necessary equipment. According to the user manual, the answer "Not applicable" was used when the respondent said that they managed themselves or thought the question was irrelevant. The interview lasted 30-90 minutes (mean 50 minutes), and included pauses when the respondent felt tired. The completed questionnaire was returned in a sealed envelope to the third author.

The interviewer was a registered nurse with further education in geriatric and psychiatric care and many years of experience working with elderly people with dementia. He wore ordinary clothes so that the respondents would not identify him as personnel. No relatives or personnel were present during the interviews.

\section{Questionnaire}

The QPP is a validated generic questionnaire developed to measure the quality of care from the patient's perspective. ${ }^{21}$ Adaptation of the QPP to make it applicable to persons with dementia ${ }^{4}$ was based on modification of the generic QPP items, ${ }^{22}$ a QPP version for adults with intellectual/developmental disability, ${ }^{25}$ and two new context-specific items based on the research team's expert knowledge. The new items that were constructed concerned the patient's freedom to go outdoors and whether they dared to tell the personnel what they thought.

A further modification comprised a simplification of the wording of most items (eg, the statement "I received the best possible physical care, eg, help to take care of my personal hygiene" was changed to "Do you receive good help to wash/take a shower?") and response alternatives, as well as a reduction in the number of response choices from four to three. In addition to simplification of the wording, all items were changed from statements to questions, as an interviewer asked the questions (eg, the statement "I decide what to do during the day" was changed to "Can you decide what to do during the day?"). ${ }^{4}$ 
For each item, the respondent was asked for two ratings. The first concerned the perceived quality of care (perceived reality), where the perceived reality of each item described the person with dementia's perceptions of the actual care received. The items were related to the sentence "What did you experience ..." (eg, "Can you decide when to get up in the morning?") and the response scale used was $1=$ no, $2=$ sometimes, and $3=$ yes. Each item also had a "Not applicable" and "Don't know" response alternative. The second rating was about the importance of that aspect of care to the respondent (subjective importance). Subjective importance that the person with dementia ascribed to various aspects of care was related to the sentence "How important is it for you that ..." (eg, "How important is it for you to decide what to do during the day?") and the response scale used was $1=$ not important, 2 = important, and 3 = very important. Each item also had a "Not applicable" and "Don't know" response alternative. The adapted QPP-DC questionnaire ${ }^{4}$ contains 26 items designed to measure the four quality dimensions of the model of quality of care from the patient's perspective: the medical-technical competence and identity-oriented approach of the caregivers and the care organization's physical-technical conditions and sociocultural atmosphere. ${ }^{20,21}$ See Tables 1 and 2 for quality dimensions and items.

\section{Statistical Analysis}

SPSS 26 was used to analyze the data. ${ }^{26}$ Frequency, percentage, and means \pm SD were used to describe the study sample and residents' perceptions of quality of care regarding the item (perceived reality) and its subjective importance. $^{26}$

\section{Ethical Considerations}

As shown in previous research that included persons with dementia, ${ }^{4,27,28}$ there are some ethical issues related to this study, one of which concerns the demands of informed consent. The purpose of informed consent is to protect especially vulnerable persons from being mistreated during research. However, the demands of informed consent might be interpreted so strictly that groups of patients might be denied participation in research. ${ }^{16}$ Persons with dementia have varying degrees of capacity, and this might change from day to day. Those participating in the study were assessed as having the competence necessary to make a decision about participating in this particular research, and written informed consent were obtained from all of them. The interviewer was flexible, and tried to adjust the time for interview to each person's condition.

This study was conducted in accordance with the Declaration of Helsinki. ${ }^{29}$ The study was approved by the Data Protection Official for Research (Norwegian Centre for Data Research) under Norwegian Social Science Data Services (735472). The Regional Committee for Medical and Health Research Ethics South-Eastern Norway assessed the research as not requiring committee recommendations (2014/2117). Respondents provided written consent to participate after being provided written and oral information about the study's aims and content. They were informed about confidentiality and the option of withdrawing at any stage without prejudice to them as residents.

\section{Results}

\section{Sample Characteristics}

The respondents' mean age were 86.7 years, and twothirds were women. More than $30 \%$ of the respondents reported their health as bad and about $53 \%$ as neither good nor bad. Only about $19 \%$ of the sample reported being satisfied with living in a nursing home, while over twothirds $(37.5 \%)$ reported being dissatisfied. The mean MMSE score (respondents' cognitive ability) was 16 . In sum, 30 of 33 respondents were assessed using the MMSE. See Table 3 for residents' characteristics and satisfaction ratings regarding living in a nursing home.

\section{Respondents' Perceptions of Care Quality}

Almost $60 \%$ of respondents reported that they received good help to wash/take a shower and $67 \%$ that this was important for them. Most respondents reported that they received $(36 \%)$ or sometimes received $(48 \%)$ good help when they were in pain. The majority answered that they did not receive good information about their medicines (70\%) and regarded such information as important to them $(91 \%)$.

Nearly half the respondents answered that they received $(15 \%)$ or sometimes received $(30 \%)$ good help and support when they felt anxious. One in four answered "I do not know" on that question. About 70\% answered that it was important for them to receive that kind of support. More than $50 \%$ reported that they only sometimes received $(30 \%)$ or did not receive $(21 \%)$ good help and support when they felt lonely, and nearly a third answered 
Table I Residents' Perceptions of Health-care Quality $(n=33)$

\begin{tabular}{|c|c|c|c|c|c|}
\hline & \multicolumn{5}{|c|}{ Perceived Reality, n (\%) } \\
\hline & Yes & Sometimes & No & $\begin{array}{l}\text { Do not } \\
\text { know }\end{array}$ & $\begin{array}{l}\text { Not } \\
\text { Applicable* }\end{array}$ \\
\hline \multicolumn{6}{|l|}{ Medical-technical competence: } \\
\hline Do you receive good help to wash/take a shower? & $19(57.6)$ & $8(24.2)$ & I (3.0) & $5(15.2)$ & - \\
\hline Do you receive good help to brush your teeth? & $6(18.2)$ & $3(9.1)$ & $2(6.1)$ & $2(6.1)$ & $20(60.6)$ \\
\hline Do you receive good help to go to the toilet? & $7(21.2)$ & $7(2 \mid .2)$ & - & - & $19(57.6)$ \\
\hline Do you receive good help from the physician? & $13(39.4)$ & $6(18.2)$ & $6(18.2)$ & $8(24.2)$ & - \\
\hline Do you receive good help when you are in pain? & $12(36.4)$ & $16(48.5)$ & $2(6.1)$ & $2(6.1)$ & I (3.0) \\
\hline Do you receive good information about your medicines? & $4(12.1)$ & $4(12.1)$ & $23(69.7)$ & - & $2(6.1)$ \\
\hline \multicolumn{6}{|l|}{ Identity-oriented approach } \\
\hline Do you receive good help and support when you feel uneasy? & $5(15.2)$ & $10(30.3)$ & $4(12.1)$ & $8(24.2)$ & $6(18.2)$ \\
\hline Do you receive good help and support when you feel lonely? & I (3.0) & $10(30.3)$ & $7(2 \mid .2)$ & $\begin{array}{l}\text { II } \\
(33.3)\end{array}$ & $4(12.1)$ \\
\hline $\begin{array}{l}\text { Do you have good opportunities to talk to someone about what } \\
\text { is on your mind? }\end{array}$ & & $12(36.4)$ & $12(26.4)$ & $6(18.2)$ & $4(12.1)$ \\
\hline Do the nurses come when you need them? & $12(36.4)$ & $14(42.4)$ & $5(15.2)$ & $\mathrm{I}(3.0)$ & $\mathrm{I}(3.0)$ \\
\hline Do the nurses have time to talk with you? & II (33.3) & $13(39.4)$ & $7(2 \mid .2)$ & I (3.0) & I (3.0) \\
\hline Do you dare to speak out if you disagree with the nurses? & $14(42.4)$ & $7(21.2)$ & I (3.0) & $2(6.1)$ & $9(27.3)$ \\
\hline Are the nurses respectful toward you? & $8(24.2)$ & $16(48.5)$ & $6(18.2)$ & $3(9.1)$ & - \\
\hline Do the nurses care about you? & $8(24.2)$ & $7(21.2)$ & $5(15.2)$ & $\begin{array}{l}10 \\
(30.3)\end{array}$ & $3(9.1)$ \\
\hline \multicolumn{6}{|l|}{ Physical-technical conditions } \\
\hline Do you get enough food? & $25(75.8)$ & $3(9.1)$ & I (3.0) & $3(9.1)$ & I (3.0) \\
\hline Do you receive dinner that you like? & $4(12.1)$ & $19(57.6)$ & $4(12.1)$ & $6(18.2)$ & - \\
\hline Do you have access to the equipment that is necessary for you? & $9(27.3)$ & I (3.0) & - & I (3.0) & $22(66.7)$ \\
\hline Do you have a comfortable bed? & $15(45.5)$ & $3(9.1)$ & II (33.3) & $4(12.1)$ & - \\
\hline \multicolumn{6}{|l|}{ Sociocultural atmosphere } \\
\hline Can you decide when to get up in the morning? & $23(69.7)$ & $8(24.2)$ & $2(6.1)$ & - & - \\
\hline Can you decide when to eat breakfast and supper? & $13(39.4)$ & $13(39.4)$ & $5(15.2)$ & $2(6.1)$ & - \\
\hline Can you decide what you want to do during the day? & $3(9.1)$ & $10(30.3)$ & $14(42.4)$ & $6(18.2)$ & - \\
\hline $\begin{array}{l}\text { Can you decide whether to be together with the others or be } \\
\text { alone? }\end{array}$ & $19(57.6)$ & $7(2 \mid .2)$ & $3(9.1)$ & $4(12.1)$ & - \\
\hline Can you decide when to go to bed? & $12(36.4)$ & $7(21.2)$ & II (33.3) & $3(9.1)$ & - \\
\hline Is it a pleasant atmosphere on the ward? & $16(48.5)$ & $8(24.2)$ & $6(18.2)$ & $2(6.1)$ & I (3.0) \\
\hline Are your relatives and friends treated respectfully? & $13(39.4)$ & $4(12.1)$ & I (3.0) & $\begin{array}{l}15 \\
(45.5)\end{array}$ & - \\
\hline Do you receive help to get outdoors? & - & $4(12.1)$ & $20(60.6)$ & $2(6.1)$ & $7(2 \mid .2)$ \\
\hline
\end{tabular}

Notes: *They handle the tasks themselves, do not experience those feelings, or do not need any equipment. Copyright permission is not required to adapt and reproduce the QPP items in Table I, but complete references to the authors who developed the questionnaire are recommended.

"I do not know." This issue was of importance to $>60 \%$ of the respondents. The majority perceived that the nurses came/or sometimes came when needed (79\%) and that they had time or sometimes had time to talk with them (73\%). Both issues were important for the respondents. Most respondents reported that they sometimes received/ received enough food (85\%), liked dinner (70\%), and decided themselves when to get up in the morning (94\%). A third reported that they did not decide when to go to bed, and $60 \%$ did not receive help to go outdoors, even though this was important to them (67\%). See Table 1 for all results. 


\section{Discussion}

The aim of the study was to describe how persons with dementia in nursing home experience the quality of care. The most thought-provoking result was that only $19 \%$ of respondents reported that they were satisfied with the way they were living at the time of the interview. This could be understood as them considering the care quality to be generally low, but that was not the case in this study. It was also interesting that almost 50\% reported that the atmosphere was pleasant in the nursing home. This thought-provoking result might be seen in light of the nursing-home residents no longer living in their "own home." Moving from one's home to a nursing home is more than just a physical move or change of address, as it influences a person's identity, sense of belonging, and well-being. ${ }^{30}$ In a previous study among persons with dementia living in nursing homes, there was great variety in the degree to which these persons considered the nursing home their home. Some residents considered it their home, but added that moving in with their children was no alternative. Others stated that it was absolutely not their home. ${ }^{28}$ Home has been described as "the place the older adult could not imagine living without"${ }^{31}$ and as an important and meaningful place, especially for older people, as home holds multiple psychological meanings and values, promotes feelings of safety, security, control, and freedom, and provides shelter, refuge, and retreat for the self, linking past experiences and preserving and providing continuity for self-identity. ${ }^{32}$ Gillsjö et al ${ }^{31}$ concluded that when older adults lose their home, they also lose the place closest to their heart: the place where they are at home and can maintain their identity, integrity, and way of living. It is worth questioning if and how nursing homes, which have a dual nature as an institution and a home, ${ }^{33}$ can best embrace the same hallmarks as a real home and whether that change could increase residents' satisfaction about where they have to live their last months or years of life.

Other interesting results were that only $15 \%$ answered that they received good help and support when they felt anxious, and $>50 \%$ that they did not or only sometimes received good help and support when they felt lonely. The majority of respondents regarded these issues as important for them. Anxiety is one of the most common behavioral and psychological symptoms in dementia ${ }^{34}$ and is known to reduce quality of life and impact on activities of daily living. ${ }^{35}$ It is thus worrisome when this is not handled properly. Concerning loneliness, living in a nursing home has earlier been described as lonely ${ }^{36}$ and boring, ${ }^{37}$ and one study found that nearly $70 \%$ of residents in nursing homes had reduced self-reported psychological wellbeing. ${ }^{11}$ Previous research has highlighted that losing autonomy or self-determination due to institutionalization is strongly related to loneliness and causes strong emotions, such as grief. ${ }^{36}$ Larsson et $\mathrm{al}^{38}$ found that older persons experienced loneliness when they were increasingly limited in body and space, due to increased dependence on others.

Loneliness is a multifaceted concept that embraces more than a number of contacts, receiving regular visits, or participating in group activities, ${ }^{36}$ and the results have to be interpreted with care. It is also noteworthy that one in three answered "I do not know" to the question "Do you receive good help and support when you feel lonely?", which might indicate that the concept is difficult to define. On the other hand, it could also indicate that they have low expectations as to whether or not the health-care personnel can help and support them when they feel lonely. The majority of respondents actually perceived that the nurses came or sometimes came when needed and that the nurses had time or sometimes had time to talk with them.

Another possible perspective is that the respondents felt lonely in their own illness. ${ }^{39}$ In this study, $>30 \%$ of the respondents reported their health condition as bad and about $53 \%$ as neither good nor bad. This is not surprising, as research has found that the prevalence of frailty increases ${ }^{40}$ among residents in nursing homes, as in the aging population in general ${ }^{41}$

In spite of rather poor self-reported health, the majority of respondents mentioned that help in going outdoors was important for them. Sadly, $60 \%$ reported that they did not receive that kind of help. Residents in nursing homes have previously expressed a desire to manage their own affairs ${ }^{42}$ and have the freedom to use outdoor space as they choose. ${ }^{43}$ The importance of having a connection with nature and the outdoors ${ }^{44}$ has been stressed as important for a person's well-being and health. ${ }^{4,45}$ To take away the possibility of going outside when this is desired can be regarded as a huge interference in a person's autonomy and sense of freedom. Nevertheless, the result here is consistent with results from previous studies, which have revealed several barriers to nursing-home residents' use of outdoor spaces. ${ }^{46}$ Issues with residents' safety and staffing are often mentioned as a concern. Too few personnel available at nursing homes and the fact that they are too busy or do not 
Table 2 Residents' Views on Importance of Health-care Quality $(n=33)$

\begin{tabular}{|c|c|c|c|c|c|}
\hline & \multicolumn{5}{|c|}{ Subjective Importance, n (\%) } \\
\hline & $\begin{array}{l}\text { Very } \\
\text { Important }\end{array}$ & Important & $\begin{array}{l}\text { Not } \\
\text { Important }\end{array}$ & $\begin{array}{l}\text { Do not } \\
\text { know }\end{array}$ & $\begin{array}{l}\text { Not } \\
\text { Applicable* }\end{array}$ \\
\hline \multicolumn{6}{|l|}{ Medical-technical competence } \\
\hline Do you receive good help to wash/take a shower? & $9(27.3)$ & $13(39.4)$ & $4(12.1)$ & $2(6.1)$ & $5(15.2)$ \\
\hline Do you receive good help to brush your teeth? & $7(2 \mid .2)$ & $2(6.1)$ & $2(6.1)$ & I (3.0) & $21(63.6)$ \\
\hline Do you receive good help to go to the toilet? & $10(30.3)$ & $4(12.1)$ & - & - & $19(57.6)$ \\
\hline Do you receive good help from the physician? & $14(42.4)$ & $16(48.5)$ & - & $3(9.1)$ & - \\
\hline Do you receive good help when you are in pain? & $20(60.6)$ & $12(36.4)$ & - & - & I (3.0) \\
\hline Do you receive good information about your medicines? & $17(5 \mid .5)$ & $13(39.4)$ & $3(9.1)$ & - & - \\
\hline \multicolumn{6}{|l|}{ Identity-oriented approach } \\
\hline Do you receive good help and support when you feel uneasy? & II (33.3) & $12(36.4)$ & - & I (3.0) & $9(27.3)$ \\
\hline Do you receive good help and support when you feel lonely? & II (33.3) & $10(30.3)$ & I (3.0) & $7(21.2)$ & $4(12.1)$ \\
\hline $\begin{array}{l}\text { Do you have good opportunities to talk to someone about what is } \\
\text { on your mind? }\end{array}$ & $6(18.2)$ & $15(45.5)$ & $5(15.2)$ & $4(12.1)$ & $3(9.1)$ \\
\hline Do the nurses come when you need them? & $14(42.4)$ & $16(48.5)$ & - & $2(6.1)$ & I (3.0) \\
\hline Do the nurses have time to talk with you? & II (33.3) & $21(63.6)$ & I (3.0) & - & - \\
\hline Do you dare to speak out if you disagree with the nurses? & II (33.3) & $8(24.2)$ & $6(18.2)$ & $3(9.1)$ & $5(15.2)$ \\
\hline Are the nurses respectful toward you? & $16(48.5)$ & $12(36.4)$ & $4(12.1)$ & I (3.0) & - \\
\hline Do the nurses care about you? & $8(24.2)$ & $18(54.5)$ & $3(9.1)$ & $3(9.1)$ & I (3.0) \\
\hline \multicolumn{6}{|l|}{ Physical-technical conditions } \\
\hline Do you get enough food? & $5(15.2)$ & $21(63.6)$ & $3(9.1)$ & $3(9.1)$ & I (3.0) \\
\hline Do you receive dinner that you like? & $3(9.1)$ & II (33.3) & $15(45.5)$ & $3(9.1)$ & I (3.0) \\
\hline Do you have access to the equipment that is necessary for you? & $2(6.1)$ & $8(24.2)$ & - & I (3.0) & $22(66.7)$ \\
\hline Do you have a comfortable bed? & $2(6.1)$ & $14(42.4)$ & $17(5 \mid .5)$ & - & - \\
\hline \multicolumn{6}{|l|}{ Sociocultural atmosphere } \\
\hline Can you decide when to get up in the morning? & $8(24.2)$ & $14(42.4)$ & $8(24.2)$ & $3(9.1)$ & - \\
\hline Can you decide when to eat breakfast and supper? & $5(15.2)$ & $13(39.4)$ & $13(39.4)$ & $2(6.1)$ & - \\
\hline Can you decide what you want to do during the day? & $15(45.5)$ & $13(39.4)$ & I (3.0) & $3(9.1)$ & I (3.0) \\
\hline $\begin{array}{l}\text { Can you decide whether to be together with the others or be } \\
\text { alone? }\end{array}$ & $15(45.5)$ & $14(42.4)$ & - & $4(21.1)$ & - \\
\hline Can you decide when to go to bed? & $7(21.2)$ & $21(63.6)$ & $5(15.2)$ & - & - \\
\hline Is it a pleasant atmosphere on the ward? & II (33.3) & $20(60.6)$ & - & I (3.0) & I (3.0) \\
\hline Are your relatives and friends treated respectfully? & $19(57.6)$ & II (33.3) & I (3.0) & $2.0(6.1)$ & - \\
\hline Do you receive help to get outdoors? & II (33.3) & II (33.3) & $2(6.1)$ & - & $9(27.3)$ \\
\hline
\end{tabular}

Notes: *They handle the tasks themselves, do not experience those feelings, or do not need any equipment. Copyright permission is not required to adapt and reproduce the QPP items in Table 2, but complete references to the authors who developed the questionnaire are recommended.

have enough time to take residents outside are barriers. ${ }^{43}$ The same barriers might possibly be an explanation for why $>40 \%$ of respondents said that they could not decide what to do during the day. The importance of feeling autonomous and the possibility of them deciding for themselves what to do and how to spend their days, ${ }^{47}$ as well as the desire to continue with some of the activities they did in their former home, ${ }^{48}$ have already been stated. $^{42}$
Nearly $60 \%$ of respondents reported that they received good help to wash/take a shower and that this was important for them. A majority reported that they could decide/ sometimes decide when to get out of bed, what to eat, when to eat, and that they received enough food. Concerning when to go to bed, the scores were quite different, as a third could not decide that important issue by themselves. Findings from previous studies have shown that nursing-home residents have limited autonomy in 
Table 3 Residents' Characteristics and Satisfaction Ratings Regarding Living in a Nursing Home $(n=33)$

\begin{tabular}{|c|c|c|c|}
\hline & n (\%) & Mean (SD) & Range \\
\hline \multicolumn{4}{|l|}{ Sex } \\
\hline Men & II (33.3) & & \\
\hline Women & $22(66.7)$ & & \\
\hline Age, years & & $86.7(6.27)$ & 74-99 \\
\hline \multicolumn{4}{|l|}{ Education } \\
\hline Compulsory school & $18(56.3)$ & & \\
\hline Upper secondary school & $10(31.3)$ & & \\
\hline University & $4(12.5)$ & & \\
\hline \multicolumn{4}{|l|}{$\begin{array}{l}\text { Self-reported health } \\
\text { condition }\end{array}$} \\
\hline Poor & $10(31.3)$ & & \\
\hline Neither good nor poor & $17(53.1)$ & & \\
\hline Good & $5(15.6)$ & & \\
\hline \multicolumn{4}{|l|}{$\begin{array}{l}\text { Satisfaction with living } \\
\text { in a nursing home }\end{array}$} \\
\hline Dissatisfied & $12(37.5)$ & & \\
\hline $\begin{array}{l}\text { Neither satisfied nor } \\
\text { dissatisfied }\end{array}$ & 14 (43.8) & & \\
\hline Satisfied & $6(18.8)$ & & \\
\hline \multicolumn{4}{|l|}{ Cognitive ability } \\
\hline $\mathrm{MMSE}^{\mathrm{a}}$ & & $16.00(5.11)$ & $8-27$ \\
\hline $\begin{array}{l}\text { Severe cognitive } \\
\text { impairment (0-9) }\end{array}$ & $2(6.7)$ & & \\
\hline $\begin{array}{l}\text { Moderate cognitive } \\
\text { impairment (10-19) }\end{array}$ & $21(70.0)$ & & \\
\hline $\begin{array}{l}\text { Mild cognitive } \\
\text { impairment (20-26) }\end{array}$ & $6(20.0)$ & & \\
\hline $\begin{array}{l}\text { No cognitive impairment } \\
(27-30)\end{array}$ & I (3.3) & & \\
\hline
\end{tabular}

Notes: ${ }^{a}$ MMSE, Mini-Mental State Examination. Scores from 0 (severe cognitive impairment) to 30 (no cognitive impairment).

deciding when to go to bed ${ }^{16}$ and generally go to bed early. Despite long hours in bed, there are frequent nighttime wakening. ${ }^{49}$ Most likely going to bed when desired can help avoid prolonging sleep latency ${ }^{49}$ and result in more satisfied and alert residents.

\section{Methodological Considerations}

This study has its limitations and strengths. The sample was rather small and the response rate just $>50 \%$. Of all 64 potential respondents in the nursing home, 37 were asked to participate. The others were not able to respond in a meaningful way, according to the personnel's judgement. Due to the high number of frail persons with severe dementia in nursing homes, this is understandable.
Among the 37 residents, four interviews were terminated, since they did not want to sign the form or were unable to respond to the questions. This can be interpreted as a confirmation that respondents satisfying the inclusion criteria were included.

This study revealed that some parts of the questionnaire need to be further developed and tested. The difference between the response alternatives "very important" and "important" on items concerning patients' subjective perception of importance seem challenging to answer.

It is considered a strength that an expert in dementia care conducted the interviews. Most respondents were positive about the interviewer's presence, and many expressed that it was nice to have a person who listened to them. Results from this study support previous research assessing care quality in nursing homes, which increases the validity of the results.

\section{Conclusion}

This study reveals that the voice of persons with dementia must be listened to in order to increase the quality of care in nursing homes. It is thought-provoking that only $19 \%$ of respondents reported that they were satisfied with living under their current circumstances. The challenge concerning how living in nursing homes can be more satisfying must be addressed by leaders and nurses in nursing homes, as well as researchers. Special attention must be paid to anxiety, loneliness, and going outdoors. The results give valuable information for quality improvement in nursing homes based on the perspective of persons with dementia.

The QPP-DC questionnaire should be further developed and tested in larger samples.

\section{Acknowledgments}

The authors are grateful to the persons who participated.

\section{Author Contributions}

All authors (AKH, DWL, and VAG) made a significant contribution to the work reported, whether in conception, study design, execution, acquisition of data, analysis and interpretation, or all these areas, took part in drafting, revising, or critically reviewing the article, gave final approval to the version to be published, have agreed on the journal to which the article has been submitted, and agree to be accountable for all aspects of the work. 


\section{Funding}

The study was funded by collaborational fundings from Østfold University College and fundings from Fylkesmannen in Østfold.

\section{Disclosure}

The authors declare that they have no conflicts of interest.

\section{References}

1. Prince M, Bryce R, Albanese E, Wimo A, Ribeiro W, Ferri CP. The global prevalence of dementia: a systematic review and metaanalysis. Alzheimer's Dementia. 2013;9(1):63-75. doi:10.1016/j. jalz.2012.11.007

2. Prince M, Ali G-C, Guerchet M, Prina AM, Albanese E, Wu Y-T. Recent global trends in the prevalence and incidence of dementia, and survival with dementia. Alzheimer's Res Therapy. 2016;8(1):23. doi:10.1186/s13195-016-0188-8

3. Winblad B, Amouyel P, Andrieu S, et al. Defeating Alzheimer's disease and other dementias: a priority for European science and society. Lancet Neurol. 2016;15(5):455-532.

4. Helgesen AK. Adaptation of the quality of care from the patient's perspective (QPP) instrument for persons with dementia. Int $J$ Pers Cent Med. 2019;7:4.

5. van Baalen A, Vingerhoets AJJM, Sixma HJ, de Lange J. How to evaluate quality of care from the perspective of people with dementia: an overview of the literature. Dementia. 2011;10(1):112-137. doi:10.1177/1471301210369320

6. Gove D, Diaz-Ponce A, Georges J, et al. Alzheimer Europe's position on involving people with dementia in research through PPI (patient and public involvement). Aging Ment Health. 2018;22(6):723-729. doi:10.1080/13607863.2017.1317334

7. Europe A. The Ethics of Dementia Research. Alzeheimer Europe; 2011.

8. Novek S, Wilkinson $\mathrm{H}$. Safe and inclusive research practices for qualitative research involving people with dementia: a review of key issues and strategies. Dementia. 2019;18(3):1042-1059. doi:10.1177/1471301217701274

9. Rivett E. Research involving people with dementia: a literature review. Working with Older People. 2017;21(2):107-114. doi:10.1108/WWOP-11-2016-0033

10. Askari M, Wierenga PC, Eslami S, Medlock S, De Rooij SE, AbuHanna A. Assessing quality of care of elderly patients using the ACOVE quality indicator set: a systematic review. PLoS One. 2011;6(12):e28631. doi:10.1371/journal.pone.0028631

11. Grøndahl VA, Fagerli LB. Nursing home care quality: a cluster analysis. Int $J$ Health Care Qual Assur. 2017;30(1):25-36. doi:10.1108/IJHCQA-12-2015-0145

12. Grøndahl VA, Fagerli LB, Karlsen H, et al. The impact of personcentered care on residents' perceptions of care quality in nursing homes: an intervention study. Int J Pers Cent Med. 2018;7(2):118124.

13. Helgesen AK, Fagerli LB, Grøndahl VA. Healthcare staff's experiences of implementing one to one contact in nursing homes. Nurs Ethics. 2019;0969733019857775.

14. McCormack B, Dewing J, McCance T. Developing person-centred care: addressing contextual challenges through practice development. Online J Issues Nurs. 2011;16(2):1-12.

15. Jogé Boumans L, van Boekel LC, Baan CA, Luijkx KG. How can autonomy be maintained and informal care improved for people with dementia living in residential care facilities: A systematic literature review. Gerontologist. 2019;59(6):e709-e730.2018. doi:10.1093/geront/gny096
16. Helgesen AK. Patient Participation in Everyday Life in Special Care Units for Persons with Dementia. Karlstads universitet; 2013.

17. Kitwood T. Dementia Reconsidered: The Person Comes First. Buckingham: Open University Press; 1997.

18. Morgan K. Dignity in dementia: A personal view. Dementia. 2011;10 (3):281-282. doi:10.1177/1471301211407804

19. Grøndahl VA. Patients' Perceptions of Actual Care Conditions and Patient Satisfaction with Care Quality in Hospital. Nursing Science, Faculty of Social and Life Sciences, Karlstads universitet; 2012.

20. Wilde B, Starrin B, Larsson G, Larsson M. Quality of care from a patient perspective: a grounded theory study. Scand J Caring Sci. 1993;7(2):113-120. doi:10.1111/j.1471-6712.1993.tb00180.x

21. Wilde B, Larsson G, Larsson M, Starrin B. Quality of care: development of a patient-centred questionnaire based on a grounded theory model. Scand J Caring Sci. 1994;8(1):39-48. doi:10.1111/j.14716712.1994.tb00223.x

22. Larsson BW, Larsson G. Development of a short form of the Quality from the Patient's Perspective (QPP) questionnaire. J Clin Nurs. 2002;11(5):681-687. doi:10.1046/j.1365-2702.2002.00640.x

23. Folstein MF, Folstein SE, Fanjiang G. Mini-Mental State Examination: Clinical Guide. Psychological Assessment Resources Lutz, FL; 2001.

24. Strobel K, Engedal K MMSE-NR, Norsk revidert Mini Mental Status Evaluering. Book MMSE-NR, Norsk revidert Mini Mental Status Evaluering Oslo: Nasjonal kompetansetjeneste $i$ aldring og helse. 2008.

25. Larsson G, Larsson BW. Quality of care and service as perceived by adults with developmental disabilities, their parents, and primary caregivers. Ment Retard. 2001;39(4):249-257. doi:10.1352/00476765(2001)039<0249:QOCASA >2.0.CO;2

26. Field A. Discovering Statistics Using IBM SPSS Statistics. sage; 2013.

27. Leavey G, Abbott A, Watson M, et al. The evaluation of a healthcare passport to improve quality of care and communication for people living with dementia (EQuIP): a protocol paper for a qualitative, longitudinal study. BMC Health Serv Res. 2016;16(1):363. doi:10.1186/s12913-016-1617-x

28. Helgesen AK, Larsson M, Athlin E. 'Patient participation' in everyday activities in special care units for persons with dementia in Norwegian nursing homes. Int J Older People Nurs. 2010;5 (2):169-178. doi:10.1111/j.1748-3743.2010.00223.x

29. Association WM. World Medical Association Declaration of Helsinki: ethical Principles for Medical Research Involving Human Subjects. JAMA. 2013;310(20):2191-2194. doi:10.1001/ jama.2013.281053

30. Brownie S, Horstmanshof L, Garbutt R. Factors that impact residents' transition and psychological adjustment to long-term aged care: A systematic literature review. Int J Nurs Stud. 2014;51 (12):1654-1666. doi:10.1016/j.ijnurstu.2014.04.011

31. Gillsjö C, Schwartz-Barcott D, von Post I. Home: the place the older adult can not imagine living without. BMC Geriatr. 2011;11(1):10. doi:10.1186/1471-2318-11-10

32. Soilemezi D, Drahota A, Crossland J, Stores R, Costall A. Exploring the meaning of home for family caregivers of people with dementia. $J$ Environ Psychol. 2017;51:70-81. doi:10.1016/j.jenvp.2017.03.007

33. Rijnaard MD, van Hoof J, Janssen BM, et al. The Factors Influencing the Sense of Home in Nursing Homes: A Systematic Review from the Perspective of Residents. J Aging Res. 2016;2016:6143645. doi:10.1155/2016/6143645

34. Majer R, Simon V, Csiba L, Kardos L, Frecska E, Hortobágyi T. Behavioural and psychological symptoms in neurocognitive disorders: specific patterns in dementia subtypes. Open Medicine. 2019;14(1):307-316. doi:10.1515/med-2019-0028

35. Brown Wilson C, Arendt L, Nguyen M, Scott TL, Neville CC, Pachana NA. Nonpharmacological interventions for anxiety and dementia in nursing homes: A systematic review. Gerontologist. 2019;59(6):e731-e742. doi:10.1093/geront/gnz020 
36. Paque K, Bastiaens H, Van Bogaert P, Dilles T. Living in a nursing home: A phenomenological study exploring residents' loneliness and other feelings. Scand J Caring Sci. 2018;32(4):1477-1484. doi:10.1111/scs.12599

37. Helgesen AK. 'A change in the men's everyday lives'-a grounded theory study. Int J Pers Cent Med. 2016;6(3):185-190.

38. Larsson H, Rämgård M, Bolmsjö I. Older persons' existential loneliness, as interpreted by their significant others - an interview study. BMC Geriatr. 2017;17(1):138. doi:10.1186/s12877-017-0533-1

39. Carel H. Illness: The Cry of the Flesh. Routledge; 2018.

40. Kojima G. Prevalence of frailty in nursing homes: a systematic review and meta-analysis. J Am Med Dir Assoc. 2015;16(11):940 945. doi:10.1016/j.jamda.2015.06.025

41. United nations EaSA. World Population Aging; 2015.

42. Tuominen L, Leino-Kilpi H, Suhonen R. Older people's experiences of their free will in nursing homes. Nurs Ethics. 2016;23(1):22-35. doi:10.1177/0969733014557119

43. Alteren J, Hermstad M, White J, Jordan S. Conflicting priorities: observation of medicine administration. J Clin Nurs. 2014

44. van Hoof J, Verbeek H, Janssen B, et al. A three perspective study of the sense of home of nursing home residents: the views of residents, care professionals and relatives. BMC Geriatr. 2016;16(1):169.
45. Buist Y, Verbeek H, de Boer B, de Bruin SR. Innovating dementia care; implementing characteristics of green care farms in other longterm care settings. Int Psychogeriatrics. 2018;30(7):1057-1068. doi: $10.1017 / \mathrm{S} 1041610217002848$

46. van den Berg MEL, Winsall M, Dyer SM, Breen F, Gresham M, Crotty M. Understanding the Barriers and Enablers to Using Outdoor Spaces in Nursing Homes: A Systematic Review. Gerontologist. 2020;60(4):e254-e269. doi:10.1093/geront/gnz055

47. Slettebø Å, Sæteren B, Caspari S, et al. The significance of meaningful and enjoyable activities for nursing home resident's experiences of dignity. Scand J Caring Sci. 2017;31(4):718-726. doi: $10.1111 /$ scs. 12386

48. Nygaard A, Halvorsrud L, Grov EK, Bergland A. What matters to you when the nursing is your home: a qualitative study on the views of residents with dementia living in nursing homes. BMC Geriatr. 2020;20(1):1-13. doi:10.1186/s12877-020-01612-w

49. Harris M, Grando V. When is nighttime? A description of bedtime in persons with dementia in the nursing home. Geriatr Nurs (Minneap). 2014;35(6):474-478. doi:10.1016/j.gerinurse.2014.06.012

\section{Publish your work in this journal}

The Journal of Multidisciplinary Healthcare is an international, peerreviewed open-access journal that aims to represent and publish research in healthcare areas delivered by practitioners of different disciplines. This includes studies and reviews conducted by multidisciplinary teams as well as research which evaluates the results or conduct of such teams or healthcare processes in general. The journal covers a very wide range of areas and welcomes submissions from practitioners at all levels, from all over the world. The manuscript management system is completely online and includes a very quick and fair peer-review system. Visit http://www.dovepress.com/testimonials. php to read real quotes from published authors. 